\title{
Effects of troglitazone on in vitro oxidation of LDL and HDL induced by copper ions and endothelial cells
}

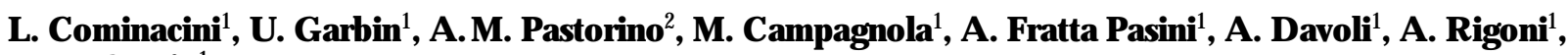 \\ V. Lo Cascio ${ }^{1}$ \\ ${ }^{1}$ I stituto di Semeiotica e N efrologia M edica, U niversità di Verona, Verona, Italy \\ ${ }^{2} \mathrm{G}$ laxoW ellcome SpA , Centro R icerche, Verona, I taly
}

Summary Troglitazone is a new oral antidiabetic agent able to reduce lipid peroxidation. In this study we evaluated its effect on the susceptibility of $L D L$ and HDL to in vitro oxidation induced by copper ions and endothelial cells. In $\mathrm{Cu}^{++}$-induced LDL modification, different amounts of troglitazone were added to aliquots of the same pool of plasma with subsequent ultracentrifuge separation of LDL and $H D L$. D ifferences in LDL and HDL susceptibility to in vitro oxidation with $\mathrm{Cu}^{++}$were studied by measuring the changes in fluorescence intensity (expressed as lag phase). LDL derived from plasma incubated with different amounts of troglitazone were also incubated with umbilical vein endothelial cells ( $\mathrm{HU}$ $V E C$ ), the modification being monitored by $L D L$ relative electrophoretic mobility and fluorescence. D uring $\mathrm{Cu}^{++}$- and HUVEC-induced LDL oxidation, the decay rate of vitamin $E$, and the potency of troglitazone as a radical scavenger in comparison with vitamin E were also studied. Troglitazone determined a significant, dose-dependent decrease in $\mathrm{Cu}^{++}$-induced LDL and HDL oxidation. Incubation with HUVEC was also followed by a progressive, significant decrease of $L D L$ relative electrophoretic mobility and fluorescence intensity. D uring $\mathrm{Cu}^{++}$- and $\mathrm{HU}$ VEC-induced-L D L modification, troglitazone significantly reduced the rate of vitamin $\mathrm{E}$ decay. In this study we also demonstrated that under the same oxidative stress, troglitazone was much more potent as a radical scavenger than vitamin $\mathrm{E}$. In conclusion, the results demonstrate that troglitazone can reduce $L D L$ and $H D L$ in vitro oxidation and that, during this process, it can protect vitamin $\mathrm{E}$. In addition to ensuring blood glucose control, the drug may therefore be useful in inhibiting lipoprotein peroxidation. [D iabetologia (1997) 40: 165-172]

Keywords $\mathrm{Cu}^{++}$, endothelial cells, LDL oxidation, oxidized LDL, troglitazone, vitamin E, alpha tocopherol, diabetes mellitus, atherosclerosis.
L ow density lipoprotein ( $L D L$ ) oxidation is believed to play an important role in the development of atherosclerotic plaques [1-5]. This view is supported by $L D L$ with characteristics similar to those of oxida-

R eceived: 26 A ugust 1996, and in revised form: 290 ctober 1996

Corresponding author: D r. L. Cominacini, I stituto di Semeiotica e N efrologia M edica, O spedale Policlinico, I-37134 Verona, I taly

A bbreviations: BCA, bicinchoninic acid; EDTA, ethylenediaminetetraacetic acid; HDL, high density lipoprotein; HPLC, high performance liquid chromatography; HUVEC, human umbilical vein endothelial cells; LD L, low density lipoprotein; $R E M$, relative electrophoretic mobility. tively modified LDL being present in atheromatous lesions [6]. Studies in cultured cells have demonstrated that oxidized LDL is chemotactic for monocytes and stimulates monocyte endothelial cell interaction $[7,8]$. It can also cause initial endothelial cell damage and increase uptake by scavenger receptors on macrophages, leading to cholesterol accumulation and foam cell formation $[7,9]$.

Oxidative modification of $L D L$ is not likely to occur in circulation [3]. In view of the difficulties in identifying oxidized lipoprotein in plasma, many workers have attempted to analyse the oxidation susceptibility of isolated LD L particles in vitro $[10,11]$. If LD L can penetrate macrophages only after its modification [3], the ability of $L D L$ to resist oxidation could be an 
important factor in atherogenesis. The progression of atherosclerotic lesions is counteracted by antioxidants such as probucol $[12,13]$ and the LD L isolated from antioxidant-treated animals shows a reduced susceptibility to in vitro oxidation [13].

$M$ any studies report increased susceptibility of $L D L$ to in vitro oxidation in patients with, or at risk of developing, atherosclerosis. This enhanced susceptibility has been observed in patients with familial hypercholesterolaemia $[14,15]$, coronary artery disease [16, 17], renal failure [18, 19], hypertension [20] and diabetes mellitus [21].

Troglitazone is a new oral antidiabetic agent reported to enhance insulin sensitivity [22], increase the conversion of glucose to glycogen in rat H epG 2 cells [22], reduce hepatic gluconeogenic enzyme activity in rats and mice [23] and to improve metabolic control in non-insulin-dependent diabetic patients [2426]. Troglitazone has also been demonstrated to reduce lipid peroxidation [27].

A therosclerosis is the major complication of diabetes, accounting for more than $70 \%$ of total mortality in all forms of the disease [28]. The extent and progression of atherosclerosis in non-human primates are related to resistance of LDL to oxidation [13]. The present study analyses the effect of troglitazone on the susceptibility of $L D L$ to oxidation induced by $\mathrm{Cu}^{++}$and endothelial cells in vitro. Since oxidative modification of high density lipoprotein (HDL) has been shown to cancel its ability to stimulate efflux of cholesterol from foam cells [29], this study al so investigates whether troglitazone can affect HDL oxidation in vitro.

\section{Materials and methods}

A ddition of troglitazone to plasma. B lood samples were collected from healthy volunteers into vacutainer tubes containing EDTA $(1 \mathrm{mg} / \mathrm{ml})$, and immediately centrifuged at $2000 \mathrm{rev} /$ $\min$ for $20 \mathrm{~min}$ at $4^{\circ} \mathrm{C}$. Plasma was pooled and different amounts of troglitazone (from 0 to $25.0 \mu \mathrm{g} / \mathrm{ml}$ plasma) were added to aliquots of the same plasma pool for $12 \mathrm{~h}$ at room temperature. The aliquots were then stored at $4^{\circ} \mathrm{C}$ and processed for separation of LDL and HDL within 3 days.

Subjects received a full verbal and written explanation of the nature and purposes of the study and each gave written informed consent prior to participation in the study. The study was conducted in accordance with the D eclaration of H elsinki.

Lipoprotein separation. LDL and HDL were isolated by sequential ultracentrifugation in $\mathrm{NaBr}$ solutions [30] containing $1 \mathrm{mg} / \mathrm{ml} \mathrm{EDTA}$ and stored at $4{ }^{\circ} \mathrm{C}$. In order to minimize LD L and HDL oxidation during isolation, all solutions used in this process were deoxygenated by bubbling with argon. $L D L$ and $\mathrm{HDL}$ were stored under nitrogen at $4^{\circ} \mathrm{C}$ in a sterile, dark environment and used within 3 days. I mmediately before oxidation tests LDL and HDL were separated from EDTA and from diffusible low molecular mass compounds, by gel filtration on PD - 10 Sephadex G -25 M gel (Pharmacia, U ppsala, Sweden) in $0.01 \mathrm{~mol} / \mathrm{l}$ phosphate-buffered saline $(136.9 \mathrm{mmol} / \mathrm{l} \mathrm{NaCl}$, $\left.2.68 \mathrm{mmol} / / \mathrm{KCl}, 4 \mathrm{mmol} / \mathrm{l} \mathrm{Na}{ }_{2} \mathrm{HPO} 4,1.76 \mathrm{mmol} / / \mathrm{KH}{ }_{2} \mathrm{PO} 4\right)$ $\mathrm{pH} 7.4$.

$L D L$ and HDL oxidation by $\mathrm{Cu}^{++}$. The method for $L D L$ and $\mathrm{HDL}$ oxidation with $\mathrm{Cu}^{++}$and for the evaluation of its susceptibility to oxidation, i.e. evaluation of the length of the lag phase, was based on the development of fluorescence during copper-catalysed LDL oxidative modification. The method, described elsewhere [11], was slightly modified for automation. B riefly, after gel-filtration to remove E DTA, the fractions eluting at the void volume were pooled, adjusted with the same buffer (10 mmol// phosphate-buffered saline, $\mathrm{pH} 7.4$ ) to a protein concentration of $0.2 \mathrm{mg} / \mathrm{ml}$ and used immediately in the presence of $1 \mu \mathrm{mol} / / \mathrm{Cu}^{++}$. The HPL C for the automatic determination of the $L D L$ and $H D L$ oxidation curve was a $G$ old system (B eckman Instruments, inc., Palo A Ito, Calif., USA ), including one pump, an autosampler (G ilson, model $232 \mathrm{Bio}$; B iolabo Instruments, M ilano, I taly) with a stirrer and temperature control, a PS2/50 IB M computer with the G old acquisition and processing data software, and a fluorescence detector (Spectrophotofluorimeter Shimadzu R F-5000, Kyoto Japan). A mixing joint and a retarding stainless-steel coil, instead of the column, were connected between the sample injection valve and the detector. The size of the retarding coil was selected to ensure a delay in reaction time, as measured from the peak retention, of about $6 \mathrm{~s}$ at a flow rate of $1 \mathrm{ml} / \mathrm{min}$. Fluorescence was checked every $20 \mathrm{~min}$, from time 0 to $260 \mathrm{~min}$.

Endothelial cell culture. Human umbilical vein endothelial cells (HUVEC) were isolated from human umbilical veins according to the method of Jaffe [31], and used at passage 2-4 as previously described [32]. The cells were grown in $75 \mathrm{~cm}^{2} \mathrm{cul}-$ ture flasks (Falcon, Becton D ickinson, L incoln Park, N ew Jersey, U SA ) filled with $10 \mathrm{ml}$ of $\mathrm{H}$ am's $\mathrm{F}-12$ medium (Sigma, St. L ouis, M 0., U SA ) containing 10\% fetal calf serum (FCS) (Seromed, Berlin, Germany), 2 mmol/l glutamine (Seromed), 30 $\mu \mathrm{g} / \mathrm{ml}$ endothelial cell growth supplement (Sigma), $100 \mu \mathrm{g} / \mathrm{ml}$ heparin (Sigma), $100 \mathrm{U} / \mathrm{ml}$ penicillin-streptomycin (Sigma), $100 \mu \mathrm{g} / \mathrm{ml}$ streptomycin (Sigma) and $2.5 \mu \mathrm{g} / \mathrm{ml}$ amphotericin (Sigma). The flasks were incubated at $37^{\circ} \mathrm{C}, 100 \%$ humidity and $5 \% \mathrm{CO}_{2}$. The medium was refreshed every 2 days. A the beginning of each experiment the cells were detached by $0.01 \%$ trypsin/E D TA (Sigma). The trypsin was inactivated by dilution, and the cells were washed and counted. Cells were plated at a concentration of 20000 cells $/ \mathrm{cm}^{2}$ on a multiwell plate $\left(9.6 \mathrm{~cm}^{2} /\right.$ well) (Falcon), grown for 3 days and then used for the incubations. A that time the cells were non-confluent $\left(0.26-0.40 \times 10^{5}\right.$ cells $\left./ \mathrm{cm}^{2}\right)$.

HUVECs were harvested and characterized in terms of acetylated LD L binding and factor V III expression, according to previously described techniques [33].

LDL oxidation by HUVEC. Endothelial cell-modified LDL was prepared by adding $1.5 \mathrm{ml}$ of serum-free $\mathrm{F}-12$ medium containing $200 \mu \mathrm{g} / \mathrm{ml} \mathrm{LDL}$ protein to each $35 \mathrm{~mm}$ well of endothelial cells, and incubating for $3,5,8,11,15$ and $22 \mathrm{~h}$ at $37^{\circ} \mathrm{C}$ in triplicate. LD L ( $200 \mu \mathrm{g}$ protein/ml) was also oxidized in the absence of cells as a control. $O$ xidation was arrested by the addition of $200 \mu \mathrm{mol} / /$ E DTA and refrigeration. LD L s corresponding to the different times of incubation were re-isolated by ultracentrifugation at density $=1.15$. The degree of $L D L$ oxidation was evaluated by monitoring $L D L$ fluorescence at 430 $\mathrm{nm}$, with excitation at $360 \mathrm{~nm}$ (Spectrophotofluorimeter Shimadzu R F -5000), as previously described [11].

Cytotoxicity evaluation. To assess cell survival, hexosaminidase, a stable cytosolic enzyme released by cells when they 
undergo lysis, was measured according to the method of $L$ andegren [34]. B riefly, the substrate for the enzyme hexosaminidase, $\mathrm{p}$-nitrophenol-N-acetyl-b-D-glucoseaminide (Sigma), was dissolved at $7.5 \mathrm{mmol} / \mathrm{l}$ in $0.1 \mathrm{~mol} / \mathrm{l}$ citrate buffer, $\mathrm{pH} 5$. The solution was then mixed with an equal volume of $0.5 \%$ Triton X-100 (Sigma) in water and added to cells in volumes of $60 \mu \mathrm{l}$, for $60 \mathrm{~min}$ at $37^{\circ} \mathrm{C}$. The reaction was blocked by addition of $50 \mathrm{mmol} / \mathrm{l}$ glycine (Sigma) buffer, $\mathrm{pH}$ 10.4. A bsorbance was measured in a Bio-R ad microplate reader (Model 450; B io-R ad L aboratories S. r. L., M ilan, Italy) at $405 \mathrm{~nm}$. R esults, expressed as percentage toxicity, were calculated as ( $E$ S) $\times 100 / M-S$, where $E$ represents the average absorbance readings from the experimental wells, $S$ the average spontaneous release and $M$ the maximum release after cell lysis.

$L D L$ vitamin $E$ time course and decay rate during $L D L$ oxidation. The time course of LDL vitamin $E$ and its initial decay rate was measured during the $\mathrm{Cu}^{++}$- and $\mathrm{HUVEC}$-catalysed LDL oxidation. LDL alpha-tocopherol was determined by a previously described HPL C method [35]. The initial rate of alpha-tocopherol decay was determined by fitting the points with a single exponential model, using a non-linear regression program based on the M arquard algorithm (E nzfitter, Biosoft, L ondon, UK ).

To assess the potency of troglitazone as a radical scavenger in comparison to vitamin $\mathrm{E}$ under the same oxidative stress, the data on vitamin $\mathrm{E}$ initial decay rates were also analysed in a previously described competitive kinetic model [36].

O ther methods. Protein was measured by the Pierce BCA protein assay reagent [37].

The extent of $L D L$ lipid peroxidation and $L D L$ apoprotein $B$ modification induced by $\mathrm{Cu}^{++}$and HUVEC was also monitored by evaluating the relative electrophoretic mobility (REM) of LDL. LDLREM, evaluated on agarose gel at the end of $\mathrm{Cu}^{++}$and $\mathrm{HUVEC}$ incubation, was expressed in terms of REM as compared to $L D L$ stored at $4^{\circ} \mathrm{C}$ for not more than 1 week.

Troglitazone concentration in LDL was measured by an H PL C system (G old system; B eckman Instruments) with ultra-violet detection.

\section{Statistical analysis}

D ifferences in lag phase, R E M and vitamin E levels and decay rate were analysed by one-way analysis of variance, followed by a multiple comparison test.

To compare mean alpha-tocopherol and fluorescence values obtained from LDL containing different concentrations of troglitazone after incubations with $\mathrm{Cu}^{++}$and $\mathrm{HUVEC}$ at different times, a three-way analysis of covariance with repeated measures was performed. The "V" BMPD program and statistical software manual was used (U niversity of California Press, Berkeley, Calif., U SA ). When significant results were obtained with the analysis of covariance, multiple comparison between the three different concentrations was performed by the Tukey test [38]. For each variable, the D unnett test [39] was used to compare the mean value at different times of incubation with the mean at time 0 .

\section{Results}

If otherwise not specifically indicated the results are expressed as mean \pm SD.

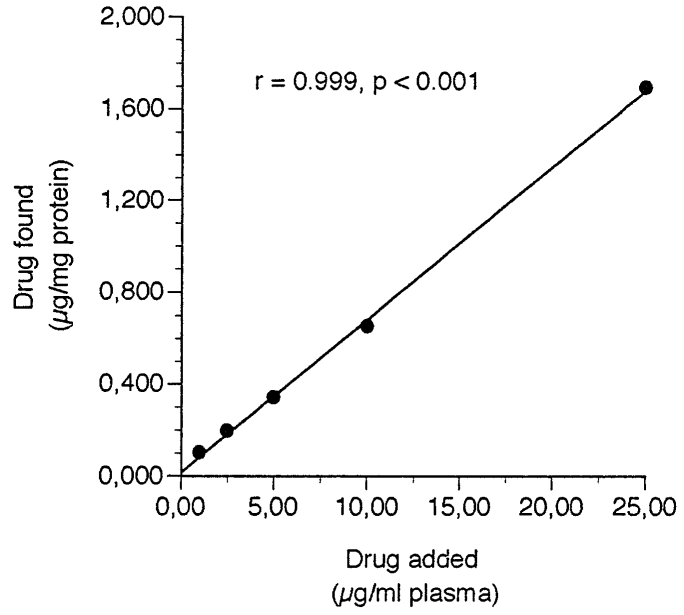

Fig. 1. Correlation between the concentration of troglitazone added to plasma and that found in LDL. Different amounts of troglitazone (from 0 to $25.0 \mathrm{\mu g} / \mathrm{ml}$ plasma) were added to aliquots of the same plasma pool for $12 \mathrm{~h}$ at room temperature. Samples were then processed by ultracentrifugation to separate $L D L$ and HDL as indicated in Materials and methods. Troglitazone in LDL was assayed as indicated in Materials and methods. $D$ ata are mean of six different assays

U nder our experimental conditions, the exposure of plasma to different amounts of troglitazone resulted in increasing LD L drug concentrations. Figure 1 shows the correlation between the concentration of troglitazone added to plasma and that found in $L D L$. The increase was a linear function of the amount added, up to $25 \mu \mathrm{g} / \mathrm{ml}$ plasma. The yield of incorporation was $6.1 \pm 1.5 \%$.

A fter incubation of plasma with increasing amounts of troglitazone, LD L and HD L were separated by ultracentrifugation. Susceptibility to oxidation (lag phase) was measured after incubation with $\mathrm{Cu}^{++}$. A typical oxidation curve of $L D L$ with, and without troglitazone (at a concentration of $10 \mu \mathrm{g} / \mathrm{ml}$ plasma), is shown in Figure 2. R esults on L D L lag phases at the different troglitazone concentrations and their absolute variations are indicated in Table 1. When compared to control conditions, a significant increase in the LD L lag phase ( + $13.2 \pm 2.1 \mathrm{~min}$ ) was observed at a drug concentration of $0.50 \mu \mathrm{g} / \mathrm{ml}$ plasma $(p<0.01)$. Starting from this concentration, the exposure of plasma to increasing amounts of troglitazone determined a dose-dependent, significant increase in LD L lag phase $(p<0.01)$.

The results of this study also show that the susceptibility of HDL to oxidation was lower, and the length of the lag phase accordingly longer in the presence of troglitazone. Figure 3 shows the HDL lag phase at different concentrations of troglitazone. At 10 and $25 \mu \mathrm{g} / \mathrm{ml}$ plasma of troglitazone, the HDL lag phase increased from $75 \pm 2.1$ to $108 \pm 1.9 \mathrm{~min}$ and $137 \pm 2.4$ min, respectively $(p<0.01)$.

A fter incubation with HUVEC, the REM of control LDL was $1.79 \pm 0.14 \mathrm{~cm}$; the presence of 


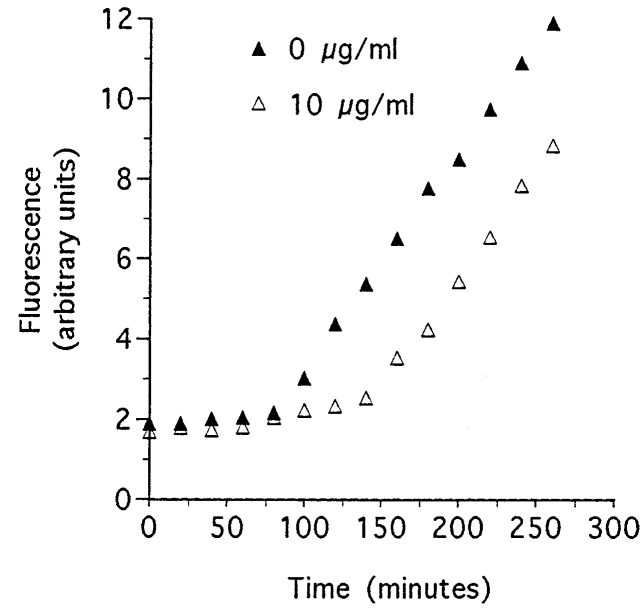

Fig. 2. Typical oxidation curve of $L D L$ induced by $\mathrm{Cu}^{++}$, without or with troglitazone $(10 \mu \mathrm{g} / \mathrm{ml}$ plasma). Troglitazone $(10 \mathrm{mg} / \mathrm{ml}$ plasma) was added to aliquots of the same plasma for $12 \mathrm{~h}$ at room temperature. Samples were then processed by ultracentrifugation to separate $L D L$ as indicated in $M$ aterials and methods. A fter gel-filtration for removing EDTA, the fractions eluting at the void volume were pooled, adjusted to a protein concentration of $0.2 \mathrm{mg} / \mathrm{ml}$ and oxidized immediately with $1 \mu \mathrm{mol} / / \mathrm{Cu}^{++}$

Table 1. E ffect of different concentrations of troglitazone added to plasma before LDL separation on LDL lag phase expressed in min and on its absolute variation in $\min (\Delta \mathrm{min})$

\begin{tabular}{lllll}
\hline $\begin{array}{l}\text { Drug added } \\
(\mu \mathrm{g} / \mathrm{ml})\end{array}$ & $\begin{array}{l}\text { D rug found } \\
(\mu \mathrm{g} / \mathrm{mg} \text { pro- } \\
\text { tein) }\end{array}$ & $\begin{array}{l}\text { Drug found } \\
(\mathrm{mol} / \mathrm{mol})\end{array}$ & $\begin{array}{l}\text { Lag-phase } \\
(\mathrm{min})\end{array}$ & \multicolumn{1}{|l}{$\begin{array}{l}\Delta \\
(\mathrm{min})\end{array}$} \\
\hline 0 & - & - & $94.0 \pm 1.1$ & \\
0.05 & ND & - & $95.6 \pm 1.2$ & $1.6 \pm 1.2$ \\
0.10 & ND & - & $95.6 \pm 1.1$ & $1.6 \pm 1.1$ \\
0.50 & ND & - & $107.2 \pm 1.4$ & $13.2 \pm 2.1$ \\
1.00 & 0.101 & 0.100 & $115.3 \pm 0.9^{\mathrm{a}}$ & $21.3 \pm 1.8$ \\
2.50 & 0.193 & 0.232 & $121.7 \pm 1.6^{\mathrm{a}}$ & $27.7 \pm 1.7$ \\
5.00 & 0.339 & 0.411 & $129.1 \pm 0.9^{\mathrm{a}}$ & $35.1 \pm 1.9$ \\
10.0 & 0.651 & 0.789 & $135.4 \pm 1.2^{\mathrm{a}}$ & $41.4 \pm 1.8$ \\
25.0 & 2.691 & 2.002 & $143.8 \pm 1.5^{\mathrm{a}}$ & $49.8 \pm 1.8$ \\
\hline
\end{tabular}

Values of drug are mean of 6 different assays

Values of lag phase are mean \pm SD of 6 different LD L oxidations

a $M$ eans of lag phases that were significantly higher $(p<0.01)$ by analysis of variance and multiple comparison test

troglitazone reduced the LD L REM to $1.25 \pm 0.10 \mathrm{~cm}$ $(p<0.01)$, to $1.04 \pm 0.09 \mathrm{~cm} \quad(p<0.01)$ and to $1.00 \pm 0.06 \mathrm{~cm}(p<0.01)$ at $2.5,5$ and $10 \mu \mathrm{g} / \mathrm{ml}$ plasma, respectively.

The degree of HUVEC-induced LDL oxidation was also evaluated by monitoring $L D L$ fluorescence at $430 \mathrm{~nm}$ with excitation at $360 \mathrm{~nm}$ at the indicated times. This was done after re-isolation of LDL from the medium by ultracentrifugation. Data on LDL fluorescence are indicated in Figure 4. The analysis of covariance showed significant differences in LD L fluorescence values between the four different troglitazone concentrations as well as between times for all

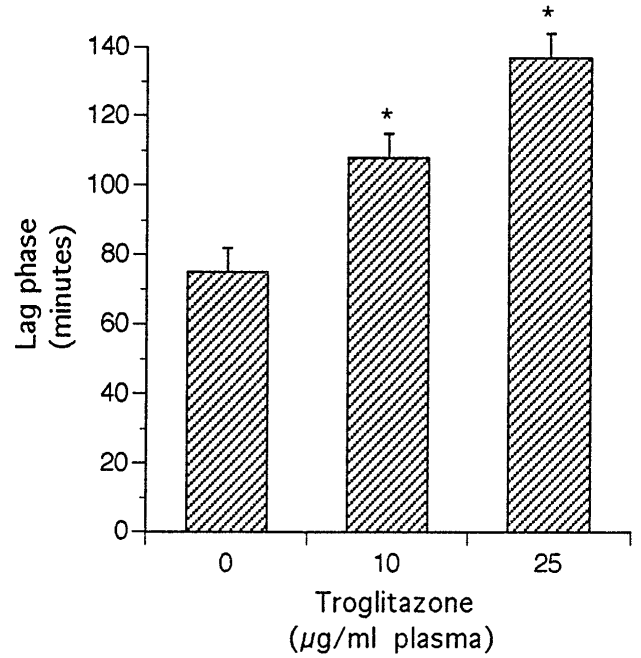

Fig. 3. D ata ( $\pm S D$ ) on HDL lag phase at different concentrations of troglitazone. Troglitazone $(10-25 \mu \mathrm{g} / \mathrm{ml}$ plasma) was added to aliquots of the same plasma for $12 \mathrm{~h}$ at room temperature. Samples were then processed by ultracentrifugation to separate HDL as indicated in M aterials and methods. A fter gel-filtration for removing EDTA, the fractions eluting at the void volume were pooled, adjusted to a protein concentration of $0.2 \mathrm{mg} / \mathrm{ml}$ and oxidized immediately with $1 \mu \mathrm{mol} / \mathrm{l} \mathrm{Cu}^{++}$. $D$ ata represent the mean of six different $H D L$ oxidations. $* p<0.01$ compared to control

four. At all concentrations, $p$ values ranged from $<0.005$ to $<0.001$.

The extent of endothelial cell cytotoxicity (expressed as percent cytotoxicity), induced by incubation with LDL ( \pm troglitazone) was always less than $3 \%$.

$L D L$ vitamin $E$ values after incubation of $L D L$ with $\mathrm{Cu}^{++}$and HUVEC provided a good fit with a single exponential decay model ( $r$ ranging from 0.90 to $0.98, p<0.001$ ). The exponential decay of $L D L$ vitamin $\mathrm{E}$ after incubation with HUVEC is shown in Figure 5.

From the monoexponential decay equations, the LDL vitamin $E$ initial decay rate was calculated. $D$ ata on $L D L$ vitamin $E$ initial decay rates are indicated in Table 2. The LDL containing increasing amounts of troglitazone showed significantly lower decay rates than control LDL $(p<0.001)$.

Starting from the assumptions that vitamin $E$ decay is due to its reaction with free radicals and that under the same oxidative stress troglitazone competes with vitamin $\mathrm{E}$ in the same reaction, the effect of troglitazone on vitamin $\mathrm{E}$ decay is assumed to be proportional to its reactivity on free radicals. Consequently the extent of vitamin $\mathrm{E}$ protection against the decomposition induced by free radicals can be considered a measure of the potency of a given radical scavenger. O $n$ the basis of these assumptions the potency of troglitazone as a radical scavenger was assessed in comparison to vitamin $\mathrm{E}$ in the following competitive kinetic model:

$\mathrm{V}_{0} / \mathrm{V}=1+\left(\mathrm{K}_{\mathrm{tr}} / \mathrm{K}_{\mathrm{e}}\right) \cdot\left(\left[\mathrm{Tr}_{0}\right] /\left[\mathrm{E}_{0}\right]\right)(1)$ where: 


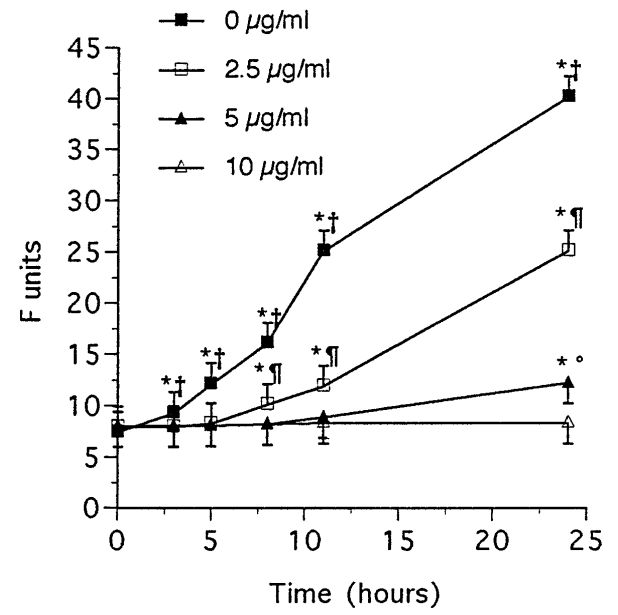

Fig. 4. D ata ( $\pm S D$ ) on the time course of $L D L$ fluorescence formation during incubation with umbilical vein endothelial cells (HUVEC) of LDL containing different concentrations of troglitazone. HU VE C-modified LD L was prepared by adding $1.5 \mathrm{ml}$ of serum-free $\mathrm{F}-12$ medium, containing $200 \mu \mathrm{g} / \mathrm{ml}$ LD L protein, to each $35 \mathrm{~mm}$ well of endothelial cells, and incubating for $3,5,8,11,15$ and $22 \mathrm{~h}$ at $37^{\circ} \mathrm{C}$. 0 xidation was arrested by the addition of $200 \mu \mathrm{mol} / \mathrm{I}$ EDTA and refrigeration. LD L s corresponding to the different times of incubation were re-isolated by ultracentrifugation at density $=1.15$. The degree of $L D L$ oxidation was evaluated by monitoring $L D L$ fluorescence, as described in $M$ aterials and methods. $D$ ata represent the mean of six different LDL oxidations. * different from time $0, p<0.001 ; \uparrow$ higher than at a plasma troglitazone concentration of $2.5,5$ and $10 \mu \mathrm{g} / \mathrm{ml}, \mathrm{p}<0.005$; - higher than at a plasma troglitazone concentration of 5 and $10 \mu \mathrm{g} / \mathrm{ml}$, $\mathrm{p}<0.001{ }^{\circ}{ }^{\circ}$ higher than at a plasma troglitazone concentration of $10 \mu \mathrm{g} / \mathrm{ml}, \mathrm{p}<0.001$

$\mathrm{V}_{0}=$ initial decay rate of $\mathrm{LDL}$ vitamin $\mathrm{E}$ without troglitazone;

$\mathrm{V}=$ initial decay rate of $L D L$ vitamin $E$ with troglitazone;

$\mathrm{K}_{\mathrm{tr}}=$ rate constant for the reaction between radicals and troglitazone

$\mathrm{K}_{\mathrm{e}}=$ rate constant for the reaction between radicals and vitamin $\mathrm{E}$

$\left[\mathrm{Tr}_{0}\right]=$ initial LDL troglitazone concentration;

$\left[E_{0}\right]=$ initial $L D L$ vitamin $E$ concentration.

In Figure 6, the scatter plot is shown for $\left[\mathrm{Tr}_{0}\right] /\left[\mathrm{E}_{0}\right]$ against $\mathrm{V}_{0} / \mathrm{V}$ after incubation of $\mathrm{LDL}$ with $\mathrm{Cu}^{++}$and HUVEC. These parameters proved to be associated ( correlation coefficient $=0.99, p<0.001$ for both $\mathrm{Cu}^{++}$and HUVEC). From the equation 1, the slope of the line, i.e. the ratio between the reactivity of troglitazone compared to vitamin $\mathrm{E}\left(\mathrm{K}_{\mathrm{tr}} / \mathrm{K}_{\mathrm{e}}\right.$ ratio), was calculated. The $\mathrm{K}_{\mathrm{tr}} / \mathrm{K}_{\mathrm{e}}$ ratio was (mean $\pm \mathrm{SE} \mathrm{M}$ ) $5.94 \pm 0.66$ after incubation with $\mathrm{Cu}^{++}$, and $57.97 \pm 6.7$ after incubation of LDL with HUVEC.

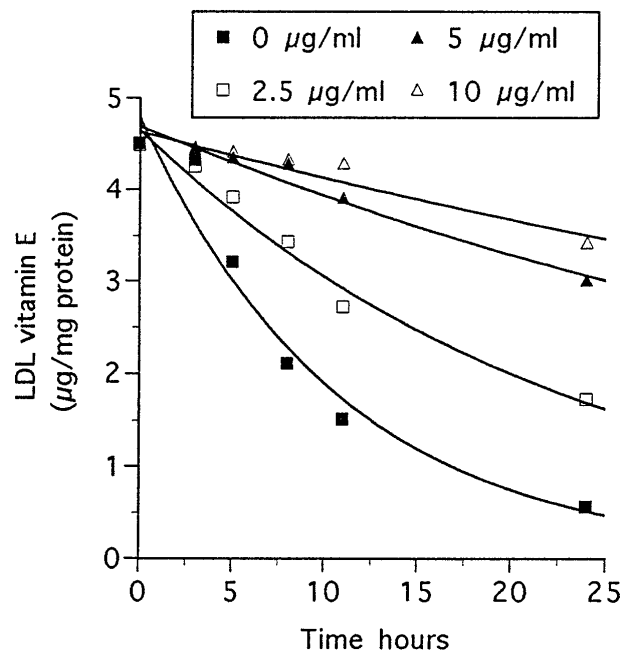

Fig. 5. Exponential decay of LD L vitamin $E$, obtained after incubation of LDL with HUVEC at different troglitazone concentrations. $D$ ifferent amounts of troglitazone (from 0 to $25.0 \mu \mathrm{g} / \mathrm{ml} \mathrm{LDL}$ ) were added to aliquots of the same plasma pool for $12 \mathrm{~h}$ at room temperature. LD L was then oxidized by HUVEC, as indicated in Materials and methods. At the indicated times, $L D L$ vitamin $E$ was measured as described in $M$ aterials and methods. The points (mean of 6 different $L D L$ oxidations) were fitted with a single exponential model by a non-linear regression program, based on the $\mathrm{M}$ arquard algorithm (see $M$ aterials and methods)

\section{Discussion}

There is growing evidence of a relationship between susceptibility of LDL to in vitro oxidation and atherosclerotic risk $[13,16,17]$. A novel strategy in the prevention of atherosclerosis could therefore be to prevent the deleterious effect of oxidized LD L by reducing the oxidation rate.

The results of this study show that troglitazone, a new oral antidiabetic agent with antioxidant capacity, decreased the susceptibility of LDL to oxidation by $\mathrm{Cu}^{++}$and HU VEC in a dose-dependent manner. A t least for the lowest concentrations, the troglitazone concentrations used in these experiments compare with the concentrations observed at therapeutic doses in human subjects. The reported median fasting plasma concentration of troglitazone at $400 \mathrm{mg}$ two times per day in healthy volunteers was $0.42 \mu \mathrm{g} / \mathrm{ml}$, while at $2 \mathrm{~h}$ post-dose it was $1.98 \mu \mathrm{g} / \mathrm{ml}$ [40].

The data for $\mathrm{LDL}$ oxidation induced by $\mathrm{Cu}^{++}$are consistent with the classic kinetic model proposed by $\mathrm{Niki}$ for lipid peroxidation [41], where the length of the lag phase is directly related to the amount of antioxidant and inversely related to the initiation rate. The amount of LDL antioxidant, under circumstances in which other variables were probably largely unaffected, is therefore critical in increasing the potential of scavenging radicals and thus delaying the initiation of the lipid peroxidation chain. O ur data are also consistent with studies in which an increase of 
Table 2. Basal $L D L$ troglitazone, $L D L$ vitamin $E$ and $L D L$ vitamin $E$ decay rates obtained after incubation of $L D L$ containing different concentrations of troglitazone with $\mathrm{Cu}^{++}$and HUVEC

\begin{tabular}{llll}
\hline & $\begin{array}{l}\text { Troglitazone } \\
(\mu \mathrm{g} / \mathrm{mg} \\
\text { protein) }\end{array}$ & $\begin{array}{l}\text { Vitamin E } \\
(\mu \mathrm{g} / \mathrm{mg} \\
\text { protein) }\end{array}$ & $\begin{array}{l}\text { D ecay rate } \\
\left(\mathrm{min}^{-1}\right)\end{array}$ \\
\hline $\mathrm{Cu}^{++}$ & 0.000 & 4.95 & $1.13 \mathrm{E}-01 \pm 0.291 \mathrm{E}-01$ \\
& 0.651 & 4.61 & $6.97 \mathrm{E}-02 \pm 0.290 \mathrm{E}-02^{\mathrm{a}}$ \\
& 1.690 & 4.51 & $3.48 \mathrm{E}-02 \pm 0.161 \mathrm{E}-02^{\mathrm{a}}$ \\
$\mathrm{HUVEC}$ & 0.000 & 4.86 & $1.53 \mathrm{E}-03 \pm 0.120 \mathrm{E}-03$ \\
& 0.193 & 4.65 & $6.99 \mathrm{E}-04 \pm 0.41 \mathrm{E}-04^{\mathrm{a}}$ \\
& 0.396 & 4.65 & $2.68 \mathrm{E}-04 \pm 02.6 \mathrm{E}-04^{\mathrm{a}}$ \\
& 0.599 & 4.61 & $1.83 \mathrm{E}-04 \pm 0.25 \mathrm{E}-04^{\mathrm{a}}$ \\
\hline
\end{tabular}

Values of troglitazone and vitamin $\mathrm{E}$ are mean of 6 different assays

D ecay rate are mean \pm SE $M$ of 6 different $L D L$ oxidations.

${ }^{a} \mathrm{p}<0.001$ (vs troglitazone $0 \mu \mathrm{g} / \mathrm{mg}$ protein)

LDL antioxidants, by incubation or oral supplementation, always resulted in a strict proportional increase in the length of the lag phase [42-44].

Troglitazone also determined a dose-dependent decrease in modification of LDL by HUVEC. A Ithough cell-mediated oxidative modification of $L D L$ has been the subject of several studies, the mechanism by which cells initiate LD L oxidation remains unclear. B oth extracellular superoxide radical [45] and lipoxygenase activity [46, 47] have been proposed. Whichever mechanism of initiation may be involved, this first led to the hypothesis that the action of the modifying cells is to accelerate formation of lipid peroxides within the LDL particle. R ecently, it has also been proposed that the modifying cells could directly provide peroxidative products to the $\operatorname{LDL}[32,48]$. Troglitazone could increase the potential of scavenging lipid peroxyl radicals, but also modify the potential of the modifying cells to produce peroxidative products and consequently delay the start of the lipid peroxidation chain.

In this study we also demonstrated that the susceptibility to in vitro oxidation of HDL derived from plasma supplemented with troglitazone was significantly lower than that of control samples. R ecently, Nagano et al. [29] reported that oxidative modification occurred in $H D L$, as in LDL. This modification resulted in denaturation of apolipoprotein $\mathrm{A} I$, with an increased negative charge [29]. I nterestingly, this modified HDL lost its ability to stimulate efflux of cholesterol from foam cells, thus suggesting that oxidative modification of HDL may stimulate development of atherosclerosis by limiting this efflux [29]. Further studies on patients at risk for atherosclerosis are needed to establish whether susceptibility of $H D L$ to in vitro modification is an important risk factor in atherogenesis.

The results of this study also show that $L D L$ vitamin $E$ levels obtained at the times of incubation with

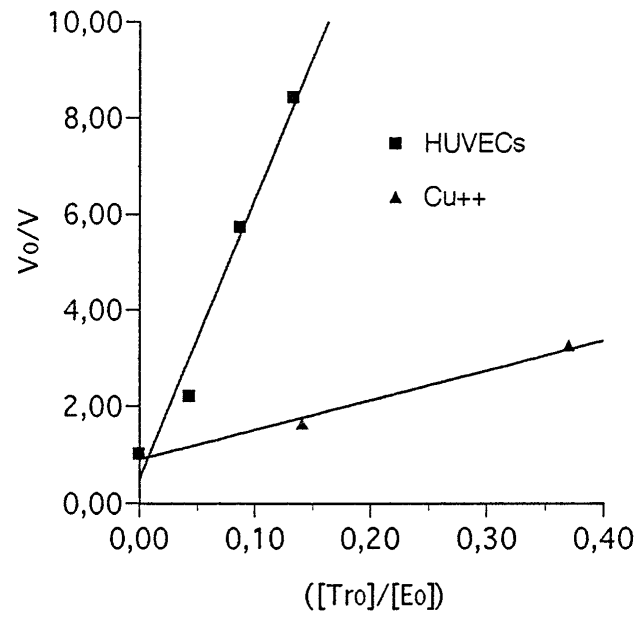

Fig. 6. Scatter plot for $\left[\mathrm{Tr}_{0}\right] /\left[\mathrm{E}_{0}\right]$ against $\mathrm{V}_{0} / \mathrm{V}$ after incubation of $L D L$ with $\mathrm{Cu}^{++}(r=0.99, p<0.001)$ and HUVEC $(r=0.99$, $p<0.001$ ). The data on vitamin $E$ initial decay rates were analysed in the following competitive kinetic model: $\mathrm{V}_{0} \mathrm{~V}=1+\left(\mathrm{K}_{\mathrm{tr}} / \mathrm{K}_{\mathrm{e}}\right) \cdot\left(\left[\mathrm{Tr}_{0}\right] /\left[\mathrm{E}_{0}\right]\right)$ where: $\mathrm{V}_{0}=$ initial decay rate of $L D L$ vitamin $E$ at $0 \mu \mathrm{g} / \mathrm{ml}$ troglitazone; $V=$ initial decay rate of $\mathrm{LDL}$ vitamin $\mathrm{E}$ with troglitazone; $\mathrm{K}_{\mathrm{tr}}=$ rate constant for the reaction between radicals and troglitazone; $\mathrm{K}_{\mathrm{e}}=$ rate constant for the reaction between radicals and vitamin $E$; $\left[\mathrm{Tr}_{0}\right]=$ initial $L D L$ troglitazone concentration; $\left[\mathrm{E}_{0}\right]=$ initial LDL vitamin E concentration

$\mathrm{Cu}^{++}$and HUVEC fitted a single exponential decay model.

A t least for $\mathrm{Cu}^{++}$-induced LDL oxidation, this is in agreement with previously reported data [42]. Troglitazone added exogenously to LDL determined dose-dependent reduction of the vitamin $E$ initial decay rate, and thus of $L D L$ vitamin $E$ consumption. $E$ ven if the mechanism underlying this protective effect of troglitazone on vitamin $E$ is unknown, one hypothesis proposed by Thomas et al. [49] is that troglitazone functions as a coantioxidant. In the model proposed by these authors, vitamin $\mathrm{E}$ does not act as a chain-breaking antioxidant, but facilitates the transfer of radical reactions from the aqueous phase into $L D L$ and mediates radical chain reactions within the lipoprotein particle. The vitamin thus exhibits prooxidant activity. Since it is the isolation of the vitamin $E$ ' within a lipoprotein undergoing oxidation that forces it to react with the polyunsaturated fatty acids of $L D L$, prevention of this oxidation depends on the rapid destruction of vitamin $\mathrm{E}^{\prime}$. This implies that a compound must have a high capacity to reduce and interact with $L D L$-associated vitamin $E$ '. The conversion of the lipophilic vitamin $E^{\prime}$ into a harmless aqueous radical is the process that actually prevents lipid hydroperoxide formation.

In this study we also demonstrated that, under equal oxidative stress, troglitazone was a much more potent radical scavenger than vitamin $\mathrm{E}$. O ur results agree with those obtained under different experimental conditions by Nagasaka et al. [50], who studied the 
effect of troglitazone and vitamin E on LD L lipid peroxidation by 2,2'-azobis(2-aminopropane) dihydrochloride. These authors found that the $50 \%$ inhibitory concentrations of troglitazone and vitamin $\mathrm{E}$ were $10 \mu \mathrm{mol} / \mathrm{l}$ and $25 \mu \mathrm{mol} / \mathrm{l}$, respectively. A Ithough the mechanism of enhanced antioxidative activity of troglitazone is not clear, it may be related to its structure. The hindered phenol of vitamin $E$ acts as a chain-breaking antioxidant, whereas the major function of the phytyl side chain is to retain the molecule in LDL [44]. The thiazolidine ring of troglitazone may affect its stability and thus its affinity for $L D L$ and hence its antioxidant capacity. Of course the present results do not preclude that, under our experimental conditions, troglitazone may protect vitamin $E$ by scavenging peroxyl radicals faster than vitamin $E$, or that vitamin $E$ can be regenerated by troglitazone as, for instance, by vitamin C [51].

Troglitazone was also shown to be much more potent than vitamin $\mathrm{E}$ when $\mathrm{LDL}$ were oxidized by $\mathrm{HU}$ $V E C$ than by $\mathrm{Cu}^{++}$. This finding raises new questions as to how HUVEC modify LDL. If the contribution of the modifying cells is only to favour LD L lipid peroxidation followed by metal-catalysed propagation, the potency of troglitazone in the $\mathrm{Cu}^{++}$and $\mathrm{HUVEC}$ model might be of the same order. If, as recently proposed $[32,48]$, the modifying cells directly provide peroxidative products to the $L D L$, a possible effect of troglitazone on production of these compounds cannot be ruled out. The present data allow no definitive conclusion on the matter and this point requires further study.

In conclusion, the results of this study demonstrate that troglitazone, in addition to ensuring blood glucose control, may be useful in inhibiting lipoprotein peroxidation, and thus slow the development of atherosclerosis in diabetes. Further studies are needed to confirm these results in the lipoproteins of diabetic patients.

\section{References}

1. A vogaro P, Bittolo B on G, Cazzolato G (1988) Presence of a modified low density lipoprotein in humans. A rteriosclerosis 8: 79-87

2. Boyd HC, G own A M, Wolfbauer G, Chait A (1989) Direct evidence for a protein recognized by a monoclonal antibody against oxidatively modified LDL in atherosclerotic lesions from a Watanabe heritable hyperlipidemic rabbit. A m J Pathol 135: 815-824

3. Steinberg D, Parthasarathy S, Carew TE, K hoo JC, Witztum J L (1989) Beyond cholesterol. Modification of lowdensity lipoprotein that increases its atherogenicity. New Engl J M ed 320: 915-924

4. Rosenfeld ME (1991) Oxidized LDL affects multiple atherogenic cellular responses. Circulation 83: 2137-2140

5. Wiklund $O, M$ attson $L, B$ jornheden $T, C$ amejo $G$, B ondjers G (1991) U ptake and degradation of low density lipoproteins in atherosclerotic rabbit aorta: role of local LDL modification. J Lipid R es 32: 55-62
6. Palinsky W, Y la-H erttuala S, R osenfeld ME, Butler SW, Socher SA, Parthasarathy S (1990) A ntisera and monoclonal antibodies specific for epitopes generated during oxidative modification of low density lipoprotein. A rteriosclerosis 10: 325-332

7. Q uinn M, Parthasarathy S, Fong LG, Steinberg D (1987) Oxidatively modified low density lipoproteins: a potential role in recruitment and retention of monocyte/macrophages during atherogenesis. Proc Natl A cad Sci 84: 29952998

8. B erliner JA, Territo MC, Sevanian A, et al. (1990) Minimally modified low-density lipoprotein stimulates monocyte endothelial interactions. J Clin Invest 85: 12601266

9. Y la-H erttuala S, Palinsky W, R osenfeld ME, et al. (1989) E vidence for the presence of oxidatively modified low density lipoprotein in atherosclerotic lesion of rabbit and man. J Clin Invest 84: 1086-1098

10. E sterbauer H J Jurgens G, Q uehenberger O, Koller E (1987) A utoxidation of human low density lipoprotein: loss of polyunsaturated fatty acids and vitamin $\mathrm{E}$ and generation of aldehydes. J Lipid Res 28: 495-509

11. Cominacini L, G arbin U, Davoli A, et al. (1991) A simple test for predisposition to $L D L$ oxidation based on the fluorescence development during copper-catalyzed oxidative modification. J Lipid R es 32: 349-358

12. Mao SJ, Yates MT, Rechtin A E, Jackson RI, Van Sickle WA (1991) A ntioxidant activity of probucol and its analogues in hypercholesterolemic Watanabe rabbits. J Med Chem 34: 298-302

13. Sasahara M, R aines E W, Chait A , et al. (1994) Inhibition of hypercholesterolemia-induced atherosclerosis in the nonhuman primate by probucol. I s the extent of atherosclerosis related to resistance of LD L to oxidation? J Clin Invest 94: 155-164

14. Lavy A, Brook GJ, Dankner G, A motz A M, A viram M (1991) E nhanced in vitro oxidation of plasma lipoprotein derived from hypercholesterolemic patients. M etabolism 40: 794-799

15. Cominacini L, Pastorino A M, Garbin U, et al. (1994) The susceptibility of $L D L$ to in vitro oxidation is increased in hypercholesterolemic patients. Nutrition 10: 527-531

16. R egnstrom J N, N ilsson J, Tornavall P, L andou C, H amsten A (1992) Susceptibility to low-density lipoprotein oxidation and coronary atherosclerosis in man. Lancet 339: $1183-1186$

17. Cominacini L, Garbin U, Pastorino A M , et al. (1993) Predisposition to $L D L$ oxidation in patients with and without angiographically established coronary artery disease. A therosclerosis 99: 63-70

18. M aggi $E$, B ellazzi R , Falaschi F, et al. (1994) E nhanced L D L oxidation in uremic patients: an additional mechanism for accelerated atherosclerosis? K idney Int 45: 876-883

19. Panzetta O, Cominacini L, Garbin U, et al. (1995) Increased susceptibility of $L D L$ to in vitro oxidation in patients on maintenance hemodialysis: effect of fish oil and vitamin E administration. Clin N ephrol 44: 303-309

20. M aggi E, M archesi $E, R$ avetta $V$, Falaschi $F$, Finardi $G$, B elIomo G (1993) L ow-density lipoprotein oxidation in essential hypertension. J H ypertension 11: 1103-1111

21. Cominacini L, Garbin U, Pastorino A M, et al. (1994) Increased susceptibility of $L D L$ to in vitro oxidation in patients with insulin-dependent and non-insulin-dependent diabetes mellitus. D iabetes R es 26: 173-184

22. Ciaraldi TP, G ilmore A, O lefsky J M (1990) In vitro studies on the action of CS-045, a new antidiabetic agent. M etabolism 39: 1056-1062 
23. Fujiwara T, Yoshioca S, Y oshioca T (1988) Characterization of new oral antidiabetic agent CS-045. Diabetes 37: 1549- 1555

24. K uzuya T, I wamoto Y, Kosaka K et al. (1991) A pilot clinical trial of a new oral hypoglycemic agent, C S-045, in patients with non-insulin-dependent diabetes mellitus. Diabetes R es Clin Pract 11: 147-153

25. M imura K, U meda F, H iramatsu S et al. (1994) E ffects of a new oral hypoglycaemic agent (CS-045) on metabolic abnormalities and insulin resistance in type 2 diabetes. $D$ iabet Med 11: 685-691

26. Kumar S, B oulton A J M , B eck-N ielsen H et al. (1996) Troglitazone, an insulin action enhancer, improves metabolic control in NID D M patients. D iabetologia 39: 701-709

27. Y oshioca T, Fujita T, K anai T (1989) Studies on hindred phenols and analogues. I. H ypolipidemic and hypoglycemic agents with ability to inhibit lipid peroxidation. J Med Chem 32: 421-427

28. Steiner C (1985) A therosclerosis, the major complication of diabetes. A dv E xp M ed B iol 189: 277-297

29. Nagano $Y$, Nakamura T, M atsuzawa $Y, C$ ho $M$, U eda $Y$, Kita T (1992) Probucol and atherosclerosis in the Watanabe heritable hyperlipidemic rabbit. Long term antiatherogenic effect and effects on established plaques. A therosclerosis 96: 131-140

30. Havel R J, E der M A , Bragdon J M (1955) The distribution and chemical composition of ultracentrifugally separated lipoproteins in human serum. J Clin Invest 34: 1345-1353

31. Jaffe EA, Nachman R L, Becker CG, Minick CR (1973) Culture of human endothelial cells derived from umbilical veins. J Clin Invest 52: 2745-2752

32. Cominacini L, Garbin U, De Santis A, et al. (1995) M echanisms involved in the in vitro modification of low density lipoprotein by human umbilical vein endothelial cells and copper ions. J Lipid M ediators Cell Signalling 13: 1933

33. Smith CW, Marlin SD, R othlein R, Toman C, A nderson DC (1989) Cooperative interactions of LFA -1 and M ac-1 with intercellular adhesion molecule-1 in facilitating adherence and transendothelial migration of human neutrophils in vitro. J Clin Invest 83: 2008-2017

34. L andegren $U$ (1984) M easurement of cell numbers by means of the endogenous enzyme hexosaminidase: application to detection of lymphokines and cell surface antigens. J Immunol M ethods 67: 379-385

35. L ehmann J, M artin H L (1982) Improved direct determination of alpha-and gamma-tocopherol in plasma and platelets by liquid chromatography, with fluorescence detection. Clin Chem 28: 1345-1353

36. von Sonntag C, Schuchmann H (1994) Suppression of hydroxyl radical reaction in biological systems: consideration based on competition kinetics. M ethod E nzymol 233: 47-56
37. Smith PK, K rohn R I, Hermanson G T et al. (1985) Measurement of protein using bicinchoninic acid. A nal Biochem 105: 293-299

38. Steel R G D, Torrie J H (1960) Principles and procedures of statistics. M cG raw-Hill, New York

39. D unnett CW (1955) A multiple comparison procedure for comparing several treatments with a control. J A m Stat A ssoc 50: 1096-1121

40. Cominacini L, Garbin U, Fratta Pasini A, Campagnola M, Young MMR, Capriati A (1996) Troglitazone increases the resistance of $L D L$ to oxidation in healthy volunteers. D iabetologia 39 [Suppl 1]:A 233 (A bstract)

41. Niki E (1987) A ntioxidants in relation to lipid peroxidation. Chem Phys Lipids 44: 227-253

42. Cominacini L, Garbin U, Cenci B, et al. (1991) Predisposition to LDL oxidation during copper-catalyzed oxidative modification and its relation to alpha-tocopherol content in humans. Clin Chim A cta 204: 57-68

43. Princen H M G, Van Poppel G, Vogelezang C, B uytenhek R, Kok RFJ (1992) Supplementation with vitamin E but not beta carotene in vivo protects low density lipoproteins from lipid peroxidation in vitro. A rterioscler Thromb 12: 554-562

44. E sterbauer H , G ebicki J, Puhl H , Jurgens G (1992) The role of lipid peroxidation and antioxidants in oxidative modifications of LD L. Free $\mathrm{R}$ ad Biol M ed 13: 341-390

45. Cathcart MA, M CNally AK, Morel DW, Chisholm GM (1989) Superoxide anion participation in human monocyte-mediated oxidation of low-density lipoprotein to a cytotoxin. J Immunol 142: 1963-1969

46. Cathcart M K, M cNally A K, Chisholm G M (1991) Lipoxygenase-mediated transformation of human low density lipoprotein to an oxidized cytotoxic complex. J Lipid Res 32: $63-70$

47. Chamulitrat W, Hughes M F, Eling TE, M ason R P (1991) Superoxide and peroxyl radical generation from the reduction of polyunsaturated fatty acid hydroperoxides by soybean lipoxygenase. A rch B iochem B iophys 290: 153-159

48. E zaki M , W itztum J L, Steinberg D (1995) L ipoperoxides in LDL incubated with fibroblasts that overexpress 15-lipoxygenase. J Lipid Res 36: 1996-2004

49. Thomas ST, N euzil J, M ohr D, Stocker R (1995) Coantioxidants make a-tocopherol an efficient antioxidant for low a density lipoprotein. A m J Clin Nutr 62: 1357-1364

50. Nagasaka Y, Kaku K, N akamura K, Kaneko T (1995) The new oral hypoglycemic agent, CS-045, inhibits the lipid peroxidation of human plasma low density lipoprotein in vitro. Biochem Pharmacol 50: 1109-1111

51. Packer JA, Slater TF, Wilson R L (1979) D irect observation of a free radical interaction between vitamin $\mathrm{E}$ and vitamin C. N ature 278: 738-741 